\title{
Single-grain quartz OSL dating of debris flow deposits from Men Tou Gou, south west
} Beijing, China

\author{
Zhao, Qiuyue ; Thomsen, Kristina Jørkov; Murray, A. S.; Wei, Mingjian ; Song, Bo
}

Published in:

Quaternary Geochronology

Link to article, DOI:

10.1016/j.quageo.2017.06.001

Publication date:

2017

Document Version

Peer reviewed version

Link back to DTU Orbit

Citation (APA):

Zhao, Q., Thomsen, K. J., Murray, A. S., Wei, M., \& Song, B. (2017). Single-grain quartz OSL dating of debris flow deposits from Men Tou Gou, south west Beijing, China. Quaternary Geochronology, 41, 62-69.

https://doi.org/10.1016/j.quageo.2017.06.001

\section{General rights}

Copyright and moral rights for the publications made accessible in the public portal are retained by the authors and/or other copyright owners and it is a condition of accessing publications that users recognise and abide by the legal requirements associated with these rights.

- Users may download and print one copy of any publication from the public portal for the purpose of private study or research.

- You may not further distribute the material or use it for any profit-making activity or commercial gain

- You may freely distribute the URL identifying the publication in the public portal 
1 Single-grain quartz OSL dating of debris flow deposits from Men Tou Gou,

2 south west Beijing, China

3

4 Qiuyue Zhao ${ }^{1,2 *}$, Kristina Jørkov Thomsen ${ }^{3}$, Andrew Sean Murray ${ }^{4}$, Mingiian Wei ${ }^{2}$,

5 Bo Song 5

$6 \quad{ }^{1}$ Key Laboratory of Tourism and Resources Environment in Universities of

7 Shandong-Taishan University, 271000 Taian, China

$8 \quad{ }^{2}$ College of Resource Environment and Tourism - Capital Normal University, 100048

9 Beijing, China

$10{ }^{3}$ Center for Nuclear Technologies, Technical University of Denmark, DTU Ris $\varnothing$

11 Campus, Frederiksborgvej 399, 4000 Roskilde, Denmark

$12{ }^{4}$ Nordic Laboratory for Luminescence Dating, Department of Geoscience, University

13 of Aarhus, Risø Campus, Frederiksborgvej 399, 4000 Roskilde , Denmark

$14 \quad{ }^{5}$ Beijing Jing Yuan School, 100040 Beijing, China

15

16

* Corresponding author: qyzhao@cnu.edu.cn

19 Abstract

20 Debris flows in the mountainous regions south west of Beijing, China occur

21 frequently and often result in considerable mass movements with disastrous

22 consequences for human life, infrastructure and agriculture. Obtaining chronological

23 information on such events is important for the prediction of the return frequency of 
24 these debris flows, risk assessment and climate change research. In this project, we use quartz single-grain optically stimulated luminescence (OSL) methods to determine the burial ages of five debris flow samples from the Zhai Tang region 60

$27 \mathrm{~km}$ west of Beijing. OSL characteristics were found to be acceptable despite the low 28 inherent brightness of quartz extracted from these samples. Single-grain thermal 29 transfer was determined to be negligible and beta dose recovery experiments were 30 satisfactory. The quartz single-grain dose distributions strongly indicate that the 31 samples were poorly bleached prior to deposition; relative over-dispersions are larger 32 than $60 \%$. Minimum age modelling indicates that all five samples were deposited 33 within the past few hundred years, indicating that catastrophic debris flows are 34 occurring under the historically-recent land-use pattern.

Keywords

Debris flows are frequent events in mountainous areas; in China they lead to the death of 300-600 people every year and annual losses of $\sim 2$ billion yuan ( US\$ 300M, Cui et al., 2000). Although catastrophic debris flows are an unavoidable component of the evolution of mountain landforms (Šilhán and Pánek, 2010), their impact can be reduced by quantifying risk in time and space. Fortunately, debris flow deposits provide a record of the size and frequency of debris flows, as well as of other agents of landscape evolution; they can reflect rainfall, terrain and tectonic movements (Cui et al., 1996). In the region of interest in this study, the mountainous area to the west of Beijing, a knowledge of the age of debris flow deposits, coupled with an understanding of the associated formation environment, hydrodynamic 
conditions, and environmental evolution would help in the understanding and assessment of the modern environment and contribute to providing estimates of the likelihood of geological disasters. Unfortunately, the interpretation of the debris flow record in terms of return frequency, risk assessment, and related climate change research is limited by the availability of reliable chronological methods; organic material suitable for ${ }^{14} \mathrm{C}$ dating is rare.

Optically Stimulated Luminescence (OSL) has the potential to determine the time elapsed since the last transport and deposition of sediment; this technique measures the time elapsed since energy trapped in crystal structures (e.g. quartz and feldspar) as a result of exposure to natural ionising radiation was last released by exposure to daylight. However, the opportunity for sufficient light exposure during debris flows is limited and thus heterogeneous resetting of the latent OSL signal is expected. Despite this, Lu et al. (2003) used fine-grain (multi-grain aliquots) OSL techniques (infrared stimulated luminescence, IRSL and green stimulated luminescence, GLSL) to date 9 debris flow deposits samples on the Ma Lan platform (south west of Beijing) and concluded that these sediments were deposited $\sim 7-43$ ka ago, i.e. before significant anthropogenic influence and likely in a substantially different climate regime; the presence of Holocene ages indicates that at least some resetting had taken place even in such unlikely environments. Nevertheless, application of standard multi-grain OSL techniques to such deposits is likely to result in a significant over-estimation of the true burial age due to averaging effects (e.g. Olley et al., 1998). Thus, in order to identify the population of grains most likely to have been well-bleached (or wellreset) at deposition, the aliquot size must be reduced, ideally to a single grain, and minimum dose modelling applied. Wu et al. (2010) investigated single grains of quartz extracted from modern debris flow deposits in western Taiwan and found that using the lowest $5 \%$ of the single-grain doses (Olley et al., 1998) helped to distinguish well-bleached grains from incompletely bleached grains. Zhao et al. (2015) applied the IEU (Internal/External Consistency Criterion, Thomsen et al., 2003; 2007) 
minimum dose model to a recent known-age ( $<25$ years) debris flow from a small $\left(\sim 3.9 \mathrm{~km}^{2}\right)$ catchment $\sim 140 \mathrm{~km}$ north of Beijing and to three palaeo-deposits from a sedimentary sequence containing the evidence of multiple flow events. They obtained an age estimate for the youngest sample consistent with the known age, and minimum ages for the older palaeo-deposits suggesting that there were at least 3 major debris flows in that catchment in the last 1000 years.

In the densely populated and mountainous region around Beijing, debris flows have repeatedly led to mortality and significant economic loss (Xie and Cui, 1992). The aim of our study is to lay the foundation for the reconstruction of debris flow activity history in the Beijing region. Because of the likelihood of incomplete bleaching, we use quartz single-grain OSL techniques. Thermal transfer and dose recovery is first investigated and burial doses for five torrent debris flow deposits from the Men Tou Gou District (Beijing) are derived by application of the IEU minimum dose model. The regional implications of the resulting ages are then considered.

\section{REGIONAL SETTING AND SITE DESCRIPTION}

The study area is situated in the Zhai Tang Zhen, in the Men Tou Gou District, Beijing (39 $\left.57^{\prime} 28.21^{\prime \prime} \mathrm{N}, 115^{\circ} 41^{\prime} 35.66^{\prime \prime} \mathrm{E}\right)$; samples were taken beside the Ma Lan Gou, a southern seasonal tributary of the Qingshui River (a tributary of Yongding River) (Fig.1). The local geology is dominated by purple and grey sand shale and sandy slate, and the catchment lies in a mid-latitude eastern continental monsoon climate, with frequent rain storms between June and August; this period delivers $\sim 75 \%$ of the annual $\sim 677 \mathrm{~mm}$ precipitation. Upstream of our sampling site, the $\mathrm{Ma}$ Lan Gou channel is $\sim 6 \mathrm{~km}$ long, with a catchment area of $\sim 15 \mathrm{~km}^{2}$ and a relative elevation of $\sim 100 \mathrm{~m}$. The steep terrain combined with intense rainstorms have led to many debris flows in the area in the historical past ( Zhao and Dong,1996; Xie et 
105 al.,2001), especially the debris flows at Qing Shui and Zhai Tang in 1950, which

106 affected 53 villages; 84 people were killed, 24 seriously injured and $>80$ houses were 107 destroyed (Hong, 1995).

108 At our site, a road cuts through debris flow facies from Ma Lan Gou (Fig. 1). The 109 exposed section sits on bedrock and is made up primarily of gravel and mixed hybrid 110 units interleaved with sandy silt deposits. The composite section of Fig. 1c is based on 111 four adjacent and laterally-connected exposures, individually illustrated in Fig. 1d.

112 Some fine sand lenses are also present. The hybrid units are poorly sorted, and contain 113 sub-rounded gravel and silty sands, with randomly oriented large clasts. These units 114 are confidently identified as debris flow deposits.

115

\section{EXPERIMENTAL DETAILS}

\section{$117 \quad 3.1 \quad$ SAMPLING}

118 The freshly exposed sections were cut vertically and cleaned. OSL dating samples 119 were collected using $5 \mathrm{~cm}$ diameter $25 \mathrm{~cm}$ long steel tubes located as shown in Fig. 1. 120 Samples ZT-1, 3 and ZT-4 were taken from the high energy hybrid units, ZT-2 and 121 ZT-5 were taken from the interleaved lower energy sandy silts (see also Table 1). We 122 interpret samples ZT-1, 2, 3 to have been deposited during the early stages of debris 123 flow, and samples ZT-4,5 to have been deposited as the mass movement ceased, or 124 afterwards. Aluminium foil was used to pack and wrap the two ends of the tube to 125 prevent sample mixing during transport. Samples preparation was carried out under 126 subdued red light and material from the two ends of the sampling tubes was removed 127 for dose rate and water content measurement; sediment from the middle part of the 128 sampling tubes was used for $\mathrm{D}_{\mathrm{e}}$ estimation (see below). 


\subsection{SAMPLE PREPARATION}

131 The material collected for OSL measurements was firstly wet-sieved to give the

$132180-250 \mu \mathrm{m}$ grain size fraction. The grains were then treated with $10 \%$ hydrochloric

133 acid $(\mathrm{HCl})$ and $10 \%$ hydrogen peroxide $\left(\mathrm{H}_{2} \mathrm{O}_{2}\right)$ to remove carbonates and organic

134 matter. Density separation used sodium polytungstate heavy liquid of density 2.58 and

$1352.70 \mathrm{~g} \mathrm{~cm}^{-3}$ to separate a quartz-rich fraction. To remove the alpha irradiated skin and

136 any remaining feldspar contamination, the quartz fractions were then etched with $40 \%$

137 hydrofluoric acid (HF) for $60 \mathrm{~min}$, and washed in $10 \% \mathrm{HCl}$ for $40 \mathrm{~min}$ to remove any

138 fluoride precipitates. Any remaining feldspar contamination in quartz was checked by

139 infrared (IR) stimulation to confirm that no samples gave a significant IR signal

140 (compared to blue OSL). All samples were re-sieved after chemical treatment to the

141 size fraction $180-250 \mu \mathrm{m}$.

\section{$143 \quad 3.3$ INSTRUMENTATION AND ANALYSIS}

144 All OSL measurements were made using Risø TL/OSL DA-20 readers (Bøtter-

145 Jensen et al., 2003; 2010). Single-grain OSL measurements were made using the Ris $\varnothing$

146 single-grain attachment. Luminescence signals were detected using a combination of 147 a bialkali EMI 9235QB photomultiplier tube and a $7.5 \mathrm{~mm}$ Hoya U-340 filter. Single

148 grain OSL measurements made use of a $10 \mathrm{~mW}$ green $\mathrm{Nd}: \mathrm{YVO}_{4}$ solid diode-pumped

149 laser emitting at $532 \mathrm{~nm}$ and providing a power density of $\sim 50 \mathrm{~W} \mathrm{~cm}^{-2}$ (Duller et al., 150 1999). Arrays of blue (470 nm) LEDs providing a power density of $\sim 40 \mathrm{~mW} \mathrm{~cm} \mathrm{~cm}^{-2}$ at

151 the sample position were used in multi-grain measurements. Green laser stimulation

152 was for $0.9 \mathrm{~s}$ at $125^{\circ} \mathrm{C}$ whereas blue LED stimulation was for $40 \mathrm{~s}$ at $125^{\circ} \mathrm{C}$.

153 For single-grain measurements individual quartz grains $(180-250 \mu \mathrm{m})$ were

154 loaded into aluminium single-grain measurement discs each containing a $10 \times 10$

155 matrix of grain holes (depth and diameter of $300 \mu \mathrm{m}$ ). For multi-grain measurements, 
quartz grains were mounted in a monolayer on $9.7 \mathrm{~mm}$ stainless steel discs using silicone oil. Each multi-grain aliquot contained about 150 grains.

Calibrated ${ }^{90} \mathrm{Sr} /{ }^{90} \mathrm{Y}$ beta sources $\left(\sim 0.1 \mathrm{~Gy} . \mathrm{s}^{-1}\right)$ fitted on the Ris $\varnothing$ TL/OSL-DA-20 readers were used for laboratory irradiations. The dose rates delivered by these beta sources varied by $<5 \%$ (standard deviation) across the sample area. Correcting for spatial non-uniformity of the sources (Lapp et al., 2012) did not result in significant changes to measured dose or over-dispersion (OD).

The single-aliquot regenerative dose (SAR) procedure (Murray and Wintle, 2000, 2003; Wintle and Murray, 2006) was used for dose estimation. A preheat of $200{ }^{\circ} \mathrm{C}$ for $10 \mathrm{~s}$, a cut heat of $180^{\circ} \mathrm{C}$, a heating rate of $5^{\circ} \mathrm{C} \mathrm{s}^{-1}$, and a 4.5 Gy test dose were used in all dose measurements. The dose response curves consisted of a minimum of three regeneration doses, a zero dose point (i.e. a measurement of recuperation) and a repeat (recycling) point. In addition, each aliquot was checked for feldspar contamination by the measurement of the IR depletion ratio (Duller, 2003). For single-grain measurements, the largest regeneration dose given was $160 \mathrm{~Gy}$; all single-grain doses larger than 160 Gy are derived using extrapolation and these dose estimates are thus likely to be less reliable.

Multi-grain signals were derived from the summation of the initial $0.64 \mathrm{~s}$ of stimulation. The immediately following $0.64 \mathrm{~s}$ of stimulation was used for background subtraction. Single-grain signals were derived from the summation of the first $0.06 \mathrm{~s}$ of the stimulation curves and the last $0.16 \mathrm{~s}$ of stimulation was used for background subtraction. Sensitivity-corrected OSL dose-response curves were fitted using a single saturation exponential function, passing through the origin.

Only $\mathrm{D}_{\mathrm{e}}$ estimates with a relative uncertainty of the natural test dose signal less than $30 \%$ were accepted $\left(\mathrm{s}_{\mathrm{Tn}}<30 \%\right)$. In addition, dose estimates were accepted only if (i) recycling and IR depletion ratios lay between 0.8 and 1.2 and (ii) sensitivity corrected recuperation signals were consistent with 0 at two standard deviations. No 
183 dose estimates could be derived for $\sim 46 \%$ of the otherwise accepted grains, because

184 the sensitivity corrected natural signal was in saturation on the laboratory dose 185 response curve.

186 These criteria led to the rejection of $99 \%$ of the measured single grains. In

187 addition, $54 \%$ of the multi-grain aliquots gave sensitivity-corrected natural signals

188 that lay at or above saturation of the laboratory dose-response curve (out of a total of

18954 aliquots of sample ZT-1, -2, -4.)

190

192

193

195

\section{DOSE RATES}

By their nature, the deposits are very heterogeneous, but every effort was made to take OSL samples at least $10 \mathrm{~cm}$ from the nearest large clast, to minimise the risk of significant perturbation of the gamma dose rate. Potentially light-exposed material $(\sim 80 \mathrm{~g})$ taken from the ends of the sample tube was ground and homogenized, cast in wax and stored for more than 21 days to ensure equilibrium between ${ }^{226} \mathrm{Ra}$ and ${ }^{222} \mathrm{Rn}$. The radionuclide concentrations were then measured using calibrated high resolution gamma spectrometers (Murray et al., 1987). Dose rates (Table 1) derived from the radionuclide concentrations of ${ }^{238} \mathrm{U},{ }^{232} \mathrm{Th}$ and ${ }^{40} \mathrm{~K}$ were derived using the conversion factors provided by Guérin et al. (2011), and the cosmic ray contribution is based on Prescott and Hutton (1994). The water content is the average of observed and saturated water content.

\section{LUMINESCENCE CHARACTERISTICS}

Multi-grain aliquots ( 150 grains each) were first measured to assess the suitability of these samples for OSL dating. Fig. 2 shows a normalised OSL decay curve from a multi-grain aliquot from sample ZT-2 (open triangles) and from calibration quartz (filled circles). The latter is known to be fast component dominated (Hansen et al, 2015), and the comparison demonstrates that the OSL signal from ZT2 is also fast-component dominated. The inset in Fig. 2 shows a typical dose response 
curve from multi-grain aliquots, fitted with a single saturating exponential function

210 passing though the origin.

\subsection{THERMAL TRANSFER AND DOSE RECOVERY}

212 Single-grain thermal transfer was measured for sample ZT-2 using a preheat of $213200{ }^{\circ} \mathrm{C}$ for $10 \mathrm{~s}$ and a cutheat of $180{ }^{\circ} \mathrm{C}$, by initially bleaching the sample using the 214 blue LEDs twice for $100 \mathrm{~s}$ with an intervening pause of 10,000 s. The resulting dose 215 distribution (Fig. 3a) has an arithmetic average dose of 340 $\pm 190 \mathrm{mGy}(\mathrm{n}=20)$. The 216 corresponding CAMul (Arnold et al., 2009) dose is $180 \pm 160$ mGy (CAMuL is used 217 because of the presence of non-positive dose estimates). We then performed three 218 beta dose recovery experiments using sample ZT-1, ZT-3 and ZT-4, respectively (Fig. $2193 b, c$, and d). The grains were loaded into the single-grain discs and bleached as before 220 prior to being given beta doses of 0.9 Gy (ZT-1, N=3000, Fig. 3c), 3 Gy (ZT-3, $221 \mathrm{~N}=3300$, Fig. 3b) and 6 Gy (ZT-4, N=2300, Fig. 3d), respectively. The resulting dose 222 recovery ratios are $0.92 \pm 0.16(n=23, O D=51 \pm 22 \%, C A M U L), 0.99 \pm 0.09(n=24$, $223 \mathrm{OD}=33 \pm 7 \%, \mathrm{CAM})$ and $0.96 \pm 0.05(\mathrm{n}=28, \mathrm{OD}=17 \pm 7 \%, \mathrm{CAM})$, respectively. We 224 deduce that our chosen SAR protocol is able to measure a laboratory dose given to 225 these samples before any thermal treatment with sufficient accuracy.

226 If we do not make use of the standard rejection criteria given in section 3.3 227 (except for $\left.\mathrm{s}_{\mathrm{T} n}<30 \%\right)$ the corresponding dose recovery ratios are $1.04 \pm 0.14(\mathrm{n}=27$, $228 \mathrm{OD}=50 \pm 16 \%), 1.02 \pm 0.07(\mathrm{n}=40, \mathrm{OD}=33 \pm 5 \%)$ and $0.96 \pm 0.05(\mathrm{n}=31, \mathrm{OD}=16 \pm 7 \%)$, 229 respectively. We conclude that applying the standard rejection criteria does not 230 significantly change the measured dose or the OD, but these criteria do reduce the 231 accepted grain population by $\sim 20 \%$, on average. 


\subsection{DE DISTRIBUTION AND ANALYSIS}

A total of $>29,000$ individual grains (at least 4,800 for each sample, see Table 2) were measured for the five natural samples. After application of the standard rejection criteria, between 0.8 and $1.0 \%$ of the grains gave results accepted into the dose distribution and the majority of these grains were only weakly luminescent; the median of the intensity of the test dose signal of the accepted grains was $8.3 \mathrm{~Gy}^{-1}$ (summed over the initial $60 \mathrm{~ms}$ of stimulation; 273 grains, 5 samples).

The five natural single-grain dose distributions are shown as scatter plots in Fig. 4, where the OSL signals from the natural test dose are plotted against the equivalent dose. The doses range broadly range between 0 and $300 \mathrm{~Gy}$, but note that dose estimates larger than 160 Gy (see section3.3) are derived by extrapolation and are not necessarily accurate. All dose distributions are significantly positively skewed with OD values ranging between $65 \pm 10$ and $138 \pm 29 \%$ and a 'leading edge' at low $D_{e}$ values. This indicates that these samples may not have been completely bleached before deposition and thus that multi-grain analysis may significantly over-estimate the time of the last deposition.

To derive realistic deposition ages, it is very likely that minimum dose modelling must be applied to the natural single-grain dose distributions in order to identify the grains most likely to have been well-bleached at deposition. Here we apply the IEU minimum dose model (Thomsen et al., 2007; Smedley 2015) making use of the results from the thermal transfer and beta dose recovery experiments described in section 5.1 as input parameters, i.e. values of $a$ and $b$ of $0.14 \pm 0.09$ and $0.35 \pm 0.17 \mathrm{~Gy}$, respectively. The grains identified as well-bleached using this approach are shown in Fig. 4 as filled symbols and the derived minimum burial doses $D_{b}$ are given in Table 2. The relative number of grains identified as well-bleached range between 13 and $50 \%$. The sample expected to be youngest (ZT- 5) has the highest proportion of wellbleached grains. 
In the above analysis, we have only included individual dose estimates which pass

the standard rejection criteria given in section 3.3, although the dose recovery

experiments showed that applying these criteria led to the rejection of $\sim 20 \%$ of the

grain population without any significant change to measured dose or over-dispersion.

If we now consider dose estimates based on all grains with $\mathrm{s}_{\mathrm{n}}<30 \%$ (i.e. not using

other standard rejection criteria), then the average ratio of $\mathrm{D}_{\mathrm{b}}$ calculated using grains passing all the rejection criteria to grains only passing $\mathrm{s}_{\mathrm{Tn}}<30 \%$ is $0.99 \pm 0.04(\mathrm{n}=5$ samples), but the average relative uncertainty on individual dose estimates is $\sim 30 \%$ larger if all standard rejection criteria are used. Thus, using the all the standard rejection criteria has no impact on the absolute minimum doses determined, but the precision of the minimum dose estimates is decreased. Similar observations have been made by Thomsen et al., (2012), Geach et al. (2015), Guérin et al. (2015b), Hansen et al. (2015), Kristensen et al. (2015), Zhao et al., (2015); Guérin et al. (2016), Thomsen et al, (2016).

Using minimum dose modelling relying on individual uncertainties to derive minimum dose is usually very dependent on the assigned uncertainties (e.g. Thomsen et al., 2007; Medialdea et al., 2014). In the above, we implicitly assumed that the dispersion observed in the beta dose recovery experiments is similar to the dispersion to be expected in a naturally well-bleached dose distribution of the same material. However, this is unlikely to be an accurate approach in samples that, for instance, were exposed to a heterogeneous environmental beta dose (e.g. Thomsen et al., 2007, Guérin et al., 2015). To investigate how sensitive our minimum dose estimates are to the size of the assigned additional uncertainty the additional uncertainty input parameter (a) was varied between 10 and $40 \%$, i.e. varied over the range of overdispersions commonly reported for well-bleached dose distributions (e.g. Arnold and Roberts, 2009). Fig. 5 shows how the estimated burial dose $D_{b}$ (normalized to the value derived using $a=14 \%$, as derived from the beta dose recovery experiments) varies as a function of $a$. For a given sample, all estimates of $\mathrm{D}_{\mathrm{b}}$ are consistent with 
each other although there is, as expected, a systematic increase in $\mathrm{D}_{\mathrm{b}}$ with $a$. The average ratio of $\mathrm{D}_{\mathrm{b}}$ calculated using an $a$ value of $40 \%$ to that calculated using a value of $14 \%$ is $1.44 \pm 0.08$ ( $\mathrm{n}=5$ samples).

\subsection{SYNTHETIC ALIQUOT RESULTS}

Although we focus on measurement of single-grains in this study, it is interesting to examine the doses that would have been measured using small multi-grain aliquots. Given the inherently low OSL sensitivity of these samples (few grains giving detectable OSL signals and most grains that are detectable have dim OSL signals), measurements of small multi-grain aliquots, each containing $\sim 100$ grains, might be expected to behave as single grains measurements, and so give dose distributions from which one could derive accurate deposition doses. As there was insufficient sample to undertake both single-grain and multi-grain measurements, we here examine the difference between these two approaches by combining the OSL signals from individual single-grain discs (each containing 100 single grains) to generate "synthetic" multi-grain aliquots. The synthetic multi-grain CAMUL doses are given in Table 2; these range between 29 and 62 Gy and are very similar to the corresponding CAMUL doses for the single-grain measurements (with the exception of sample ZT-2). However, none of these synthetic aliquots give doses smaller than 2 Gy and thus minimum dose modelling would significantly overestimate that of single-grain minimum dose modelling (see Table 2). Thus, despite of the low OSL sensitivity of these samples, multi-grain measurements ( 100 grains per aliquot) are likely to produce significant overestimates of the burial age compared to those provided by true single-grain measurements. 
The resulting single-grain OSL ages are given in Table 2. The five weighted 315 average $\left(\mathrm{CAM}_{\mathrm{UL}}\right)$ ages range from $7 \pm 1$ to $22 \pm 4 \mathrm{ka}$, similar to that from the synthetic 316 multi-grain ages $(13 \pm 3$ to $24 \pm 4 \mathrm{ka})$ and to fine-grain IRSL and GLSL results reported 317 by Lu et al., 2003. However, these average ages are affected by incomplete bleaching 318 and thus significantly overestimate the burial age.

319 It is likely that minimum dose modelling of single-grain dose distributions 320 provides a more accurate estimate of the burial dose. However, the calculated 321 minimum doses from minimum dose modelling are dependent on the size of the 322 assigned uncertainties (see Fig. 5). In the literature, it has often been argued that a 323 "typical" over-dispersion for well-bleached samples is $15-20 \%$ (e.g. Arnold et al., 324 2008; Demuro et al., 2008; Turney et al., 2008), i.e. an additional uncertainty of 15$32520 \%$ should be added to estimates of uncertainty based on intrinsic sources of 326 variability (e.g. Poisson statistics, curve fitting errors etc.). Others (e.g. Thomsen et 327 al., 2007; Medialdea et al., 2014; Sim et al., 2014) have argued that it would be more 328 appropriate to use an additional uncertainty based on the over-dispersion determined 329 in laboratory dose recovery experiments (preferably irradiated using a gamma 330 source), although the latter approach presumably underestimates for samples exposed 331 to significant dose rate heterogeneity during burial. However, Guérin et al. (2015) 332 showed beta dose heterogeneity arising from non-uniform distribution of potassium in 333 the sediment is of concern "when the average grain size is in the sand and gravel 334 range (rather than silt or clay), the potassium content is low $(<1 \%)$, and the total 335 dose rate is small $\left(<1 G k^{-1}\right)^{\prime}$ ". Thus, at this stage, it is less likely that our samples 336 are significantly affected by beta dose rate heterogeneity. In any case, based on the 337 beta dose-recovery experiments, the minimum uncertainty with which an individual 338 dose estimate can be known is $14 \pm 9 \%$, although we acknowledge that this over339 dispersion may be underestimated. Nonetheless, this minimum additional uncertainty 
must be added (in quadrature) to the uncertainties assigned to individual dose

estimates based on Poisson statistics and dose response curve fitting errors, if a true

minimum estimate of uncertainty on individual single grain dose estimates is to be used in later analysis.

The minimum single-grain (IEU) ages (using an additional uncertainty of $14 \%$,

345 see Table 2) are all consistent with an average age of $320 \pm 25 \mathrm{y}$ and there appears to

346 be no stratigraphic relationship between ages of the samples. If an additional

347 uncertainty of $40 \%$ is assumed, all IEU ages are consistent with an average age of

$348470 \pm 50 \mathrm{y}$. Thus, we conclude that these debris flow samples were all deposited in a

349 short span of time ( $<100$ years) within the last 500 years.

Giving the influence of insufficiently bleached grains on the OSL signal in

351 these debris flows, the single-grain ages are much smaller than those from multi-grain

352 measurements (Lu et al., 2003) and simulated multi-grain data. These debris flows

353 were apparently deposited around 300-500 y ago, during the Little Ice Age in China

354 ( Zhu et al.,1973), which may indicate an association of debris flows in this area with

355 cold periods or perhaps unstable periods of cold and warm fluctuation.

356 However, the importance of the anthropogenic-induced deterioration of the 357 regional natural environment must also be considered. According to historical 358 documents (Hou et al., 1985), significant deforestation in Xishan (Zhai Tang is in the 359 Xishan mountain basin) in this period was associated with the Yuan Dynasty (AD 360 1271-1368) construction of a new capital in Beijing. Initially, a large amount of 361 building construction material, and charcoal for cooking and heating, was taken from 362 Xishan. Subsequently during the Ming Dynasty (AD 1368-1644), Beijing's

363 increasing demand for raw materials continued the unsustained exploitation of the 364 vegetation of the Xishan region. This was exacerbated by the increase in local 365 population, which more than doubled from 300,000 to 670,000 ; this must also have 366 increased pressure on agriculture. The resulting landscape degradation presumably led 
367 to increased runoff; certainly there were frequent floods from $\sim 650$ to $\sim 360$ years ago

368 in the Lugu (now Yongding) River, into which the Ma Lan Gou feeds (Hou et al.,

369 1985). We deduce that the Zhai Tang debris flow deposits may represent geological

370 evidence for the prolonged destruction of forest resources after the establishment of

371 Yuan Dynasty capital in Beijing.

\section{CONCLUSION}

OSL dating of these debris flow deposits has proved challenging because of significant incomplete bleaching and the inherently low luminescence sensitivity of individual grains. Equivalent dose distributions are significantly positively skewed, with clearly identifiable leading edges at low doses. Using doses derived from simulated multi-grain data (synthetic aliquots) the ages of these deposits range between $13 \pm 3$ and $24 \pm 4$ ka, very similar to previously published fine-grain ages $(\mathrm{Lu}$ et al., 2003) and average single-grain ages. However, using single-grain dose distributions in combination with minimum dose modelling, the relative number of grains identified to be well-bleached range between 13 and 50\%, strongly suggesting that multi-grain OSL techniques greatly overestimated the burial ages for these samples. We conclude that these debris flow samples were probably all deposited in a short span of time $(<100$ years) within the last 500 years, and tentatively associate

386 these sediments with the historically-recorded catchment exploitation. Our results are 387 of direct relevance to the assessment of mass movement hazard in the Men Tou Gou 388 District, and we conclude that there is no evidence to suggest that the current risk of further debris flows has been mitigated. 
394 This research was supported by the National Natural Science Foundation of China 395 (NSFC, Grant No. 40871017, 41602353, 41471007 and 41301006 ) and Social Science 396 Foundation of China (Grant No. 15CJY073). We are indebted to Yanyan Tian, Rui 397 Zhou, Hongyi Chen, Yugeng Liu and Jian Pan for assistance during field work. We 398 thank Shuzhen Peng and Min Ding for providing valuable comments on this 399 manuscript. 
403 Arnold, L.J., Roberts, R.G., Galbraith, R.F., Delong, S.B., 2009. A revised burial dose 404 estimation procedure for optical dating of young and modern-age sediments. Quat. 405 Geochronol. 4, 306-325.

406 Bøtter-Jensen, L., Andersen, C.E., Duller, G.A.T., Murray, A.S., 2003. Developments 407 in radiation, stimulation and observation facilities in luminescence measurements. $408 \quad$ Radiat. Meas. 37, 535-541.

409 Bøtter-Jensen, L., Thomsen, K.J., Jain, M., 2010. Review of optically stimulated 410 luminescence (OSL) instrumental developments for retrospective dosimetry. $411 \quad$ Radiat. Meas. 45, 253-257.

412 Cui, P., Liu, S.J., Tan, W.P., 2000. Progress of debris flow forecast in China. Journal 413 of Natural Disasters. 9 (2): 10-15 (in Chineses).

414 Cui, Z.J., 1996. Debris flow deposit and environment. China Ocean Press, Beijing, 1415188 (in Chineses).

416 Duller, G.A.T., Bøtter-Jensen, L., Murray, A.S., Truscott, A.J., 1999. Single grain 417 laser luminescence (SGLL) mesurements using a novel automated reader. Nucl. 418 Instrum. Methods Phys. Res. B: Beam Interact. Mater. Atoms. 155(4), 506-514.

419 Duller, G.A.T., 2003. Distinguishing quartz and feldspar in single grain luminescence 420 measurements. Radiat. Meas. 37, 161-165.

421 Fuchs, M., Straub, J., Zöller, L., 2005. Residual luminescence signals of recent river 422 flood sediments: a comparison between quartz and feldspar of fine-and coarse423 grain sediments. Ancient TL. 23(1), 25-30. 
Geach, M. R., Thomsen, K. J., Buylaert, J.-P., Murray, A. S., Mather, A. E., Telfer, M. W., 2015. Single-grain and multi-grain OSL dating of river terrace sediments in the Tabernas Basin, SE Spain. Quat. Geochron. 2015, 213-218.

Godfrey-Smith, D.I., Huntley, D.J., Chen, W.H., 1988. Optical dating studies of quartz and feldspar sediment extracts. Quat. Sci. Rev. 7(3 4), 373-380.

Guérin, G., Mercier, N., Adamiec, G., 2011. Dose-rate conversion factors: update. Ancient TL, 29, 5-8.

Guérin, G., Jain, M., Thomsen, K., Murray, A., Mercier, N., 2015. Modelling dose rate to single grains of quartz in well-sorted sand samples: the dispersion arising from the presence of potassium feldspars and implications for single grain OSL dating, Quaternary Geochronology, 27, 52-65.

Guérin, G., Combès, B., Lahaye, C., Thomsen, K.J., Tribolo, C., Urbanova, P., Guibert, P., Mercier, N., Valladas, H., 2015a. Testing the accuracy of a Bayesian centraldose model for single-grain OSL, using known-age samples. Radiation Measurements 81, 62-70

Guérin, G., Frouin, M., Talamo, S., Aldeias, V., Bruxelles, L., Chiotti, L., Dibble, H.L., Goldberg, P., Hublin, J.-J., Jain, M., Lahaye, C., Madelaine, S., Maureille, B., McPherron, S.P., Mercier, N., Murray, A.S., Sandgathe, D., Steele, T.E., Thomsen, K.J., Turq, A., 2015b. A multi-method luminescence dating of the Palaeolithic sequence of La Ferrassie based on new excavations adjacent to the La Ferrassie 1 and 2 Skeletons. J. Archaeol. Sci. 58, 147-166.

Guérin, G., Frouin, M., Tuquoi, J.; Thomsen, K.J., Goldberg, P., Aldeias, V., Lahaye, Ch., Mercier, N., Guibert P., Jain, M., Sandgathe, D., McPherron, S.P., Turq, A., Dibble, H.L., 2016. The complementarity of luminescence dating methods illustrated on the Mousterian sequence of the Roc de Marsal: A series of reindeerdominated, Quina Mousterian layers dated to MIS 3. Quaternary International, in press. 
Hansen, L., Funder, F., Murray, A.S., Mejdahl, V., 1999. Luminescence dating of the last Weichselian Glacier advance in East Greenland. Quat. Sci. Rev. 18(2), 179190.

Hansen, V., Murray, AS., Buylaert, J-P., Yeo, E-Y., Thomsen, KJ. 2015. A new irradiated quartz for beta source calibration. Radiation Measurements 81, 123127.

Hong, C,S., 1995. Occurrence and Countermeasures of debris flow in Beijing. Beijing water conservancy. 4: 7-10.

Hou, R.Z., 1985. The Historical Atlas of Beijing. Beijing Press. pp. 127(in Chinese).

Jain, M., Murray, A.S., Bøtter-Jensen, L., 2003. Characterisation of blue-light stimulated luminescence components in different quartz samples: implications for dose measurement. Radiat. Meas. 37(4-5), 441-449.

Kristensen, J.A., Thomsen, K.J., Murray, A.S., Buylaert, J.P., Jain, M., BreuningMadsen, H., 2015. Quantification of termite bioturbation in a savannah ecosystem: application of OSL dating. Quat. Geochronol. 30, 334-341.

Lapp, T., Jain, M., Thomsen, K.J., Murray, A.S., Buylaert, J.P., 2012. New luminescence measurement facilities in retrospective dosimetry. Radiat. Meas.47, 803-808. 611-620.

Lu, Y.C., Wei, L.Y., Yin, J.H., Yin, G.M., Zhao, H., 2003. Dates and environments of the Malan gravel formation as the torrent debris deposits along Qingshui River in western hills, Beijing. Quaternary Sciences. 23(6), 611-620.

Medialdea, A., Thomsen, K.J., Murray, A.S., Benito, G., 2014. Reliability of equivalent-dose determination and age-models in the OSL dating of historical and modern palaeoflood sediments. Quat. Geochronol. 22, 11-24.

Mejdahl, V., 1987. Internal radioactivity in quartz and feldspar grains. Ancient TL. 5, 
Murray, A.S., Marten, R., Johnston, A., Martin, P., 1987. Analysis for naturally

478 occurring radionuclides at environmental concentrations by gamma spectrometry. J.

479 Radioanal. Nucl. Chem. 115(2), 263-288.

Murray, A.S., Wintle, A.G.,2000. Luminescence dating of quartz using an improved single-aliquot regenerative-dose protocol. Radiat. Meas. 32, 57-73.

Murray, A.S., Wintle, A.G., 2003. The single aliquot regenerative dose protocol: potential for improvements in reliability. Radiat. Meas. 47(9), 688-695.

Murray, A.S., Thomsen, K.J., Masuda, N., Buylaert, J.P., Jain, M., 2012. Identifying well-bleached quartz using the different bleaching rates of quartz and feldspar lumine scence signals. Radiat. Meas. 47(9), 688-695.

Olley J.M., Caitcheon G.C., and Murray A.S., 1998. The distribution of apparent dose as determined by optically stimulated luminescence in small aliquots of fluvial quartz: implications for dating young sediments. Quaternary Science Reviews (Quaternary Geochronology) 17, 1033-1040.

Prescott, J.R., Hutton, J.T., 1994. Cosmic ray contributions to dose rates for luminescence and ESR: large depths and long-term time variations. Radiat. Meas. 23, 497-500.

494 Šilhán, K., Pánek, T., 2010. Fossil and recent debris flows in medium-high mountains 495 (Moravskoslezské Beskydy Mts, Czech Republic). Geomorphology. 124, 238249. 2014. Dating recent floodplain sediments in the Hawkesbury-Nepean river system using single grain quartz OSL. Boreas,43(1), 1-21. 
Thomsen, K. J., Murray, A. S., Bøtter-Jensen, L., Jungner, H., 2003. Variation with depth of dose distributions in single grains of quartz extracted from an irradiated concrete block. Radiation Measurements, 37 (4-5), 315-321.

503 504

Thomsen, K.J., Murray, A.S., Bøtter-Jensen, L., Kinahan, J., 2007. Determination of burial dose in incompletely bleached fluvial samples using single grains of quartz. Radiat. Meas. 42 (3), 370-379.

Thomsen K.J., Murray A., Jain M., 2012. The dose dependency of the over-dispersion of quartz OSL single grain dose distributions. Radiation Measurements 47,732739.

Thomsen, K. J., Murray, A. S., Buylaert, J. P., Jain, M., Hansen, J. H., Aubry, T., 2016. Testing single-grain quartz OSL methods using sediment samples with independent age control from the Bordes-Fitte rockshelter (Roches d'Abilly site, central France). Quat. Geochron. 31, 77-96.

Wintle, A.G., 1973. Anomalous fading of thermoluminescence in mineral samples. Nature. 245, 143-144.

Wintle, A.G., Murray, A.S., 2006. A review of quartz optically stimulated luminescence characteristics and their relevance in single-aliquot regeneration dating protocols. Radiat. Meas. 41, 369-391.

Wu, T. S., Jaiswal, M.K., Lin, Y.N., Chen, Y.W., Chen, Y.G., 2010. Residual luminescence in modern debris flow deposits from western Taiwan: A single grain approach. J Asian Earth Sci. 38, 274-282.

Xie, H., Zhong, D.L., Jin, H.C., 2001. Debris flow and landslide disasters control in Mountain area of Beijing Cicy. Bulletin of Soil and Water Conservation. 21(3):37-45(In Chinese). 
524 Xie, Y.Y., Cui, Z.J., 1992. Prevention and forecast of debris flow in Beijing mountain 525 area. Guizhou Science. 3, 132(In Chinese).

526 Zhao, B., Dong, G.Z., 1996. Mud-rock flows and its dangerous prediction in the 527 drainage area of the Qingshui River, Xishan Mt., Beijing. Geology of Beijing. 3: 528 1-14(In Chinese).

529 Zhao, Q., Thomsen, K.J., Murray, A.S., Wei, M., Pan, B., Song, B., Zhou, R., Chen, 530 S., Zhao, X., Chen, H., 2015. Testing the use of OSL from quartz grains for dating 531 debris flows in Miyun, northeast Beijing, China. Quaternary Geochronology. 30, $532 \quad 320-327$.

533 Zhu, K.Z., 1873. A preliminary study on climate change in China in recent 5000 534 years. Science in China (B). 3(02): 115-120(In Chinese). 
Figure 1: Location of the study site. (a) Regional map of study area. (b) Composite section based on the four adjacent sampled sections illustrated in (c).

Figure 2: $\quad$ Multi-grain $(\sim 150$ grains $)$ quartz OSL characteristic for sample ZT-2 (preheat $200{ }^{\circ} \mathrm{C}$ for $10 \mathrm{~s}$, cutheat $180{ }^{\circ} \mathrm{C}$ ). (a) Normalised luminescence signals from calibration quartz (filled circle) and ZT-2 (open triangles). (b) Representative dose response curve for sample ZT-2 showing recycling and recuperation (open square and diamond symbols, respectively) and the interpolation of the sensitivity-corrected natural signal (filled circle) onto the dose response curve.

Figure 3: (a) Single-grain thermal transfer dose distribution for sample ZT-2. (b)-

(d) Single-grain beta dose recovery distribution for samples ZT-3 (given dose of 3 Gy), ZT-1 (0.9 Gy) and ZT-4 (6 Gy), respectively.

Figure 4: Single-grain dose distributions (open symbols) for the five natural samples. The natural test dose response ( $4.5 \mathrm{~Gy})$ is shown as a function of estimated dose. Filled symbols represents the grains identified by the

Figure 5: Variation of the estimated burial dose $\mathrm{D}_{\mathrm{b}}$ (normalized to the value using $a=14 \%$ ) as a function of the additional uncertainty input parameter $a$. 


\begin{tabular}{|c|c|c|c|c|c|c|c|c|c|}
\hline \multirow{2}{*}{$\begin{array}{c}\text { Sample } \\
\text { code }\end{array}$} & \multirow{2}{*}{$\begin{array}{l}\text { Depth } \\
\text { (m) }\end{array}$} & \multirow{2}{*}{$\begin{array}{l}\text { w.c. } \\
(\%)\end{array}$} & \multicolumn{4}{|c|}{ Radionuclide (Bq/ kg) } & \multicolumn{3}{|c|}{ Dose rate $(\mathrm{Gy} / \mathrm{ka})$} \\
\hline & & & $\mathrm{U}-238$ & Ra-226 & Th-232 & $\mathrm{K}-40$ & $\operatorname{dry} \beta$ & dry $\gamma$ & Total \\
\hline $\mathrm{ZT}-1$ & 10 & 22 & $37 \pm 15$ & $27 \pm 1.1$ & $38.3 \pm 1.2$ & $527 \pm 18$ & $1.77 \pm 0.07$ & $1.06 \pm 0.03$ & $2.35 \pm 0.14$ \\
\hline $\mathrm{ZT}-2$ & 9 & 10 & $27 \pm 12$ & $27 \pm 0.9$ & $41.1 \pm 0.9$ & $595 \pm 18$ & $1.91 \pm 0.06$ & $1.14 \pm 0.03$ & $2.61 \pm 0.16$ \\
\hline ZT-3 & 8 & 14 & $26 \pm 15$ & $31 \pm 1.2$ & $44.3 \pm 1.2$ & $574 \pm 22$ & $1.89 \pm 0.08$ & $1.19 \pm 0.04$ & $2.77 \pm 0.18$ \\
\hline $\mathrm{ZT}-4$ & 3 & 26 & $33 \pm 10$ & $27 \pm 0.8$ & $42.3 \pm 0.8$ & $551 \pm 13$ & $1.84 \pm 0.05$ & $1.13 \pm 0.03$ & $2.22 \pm 0.11$ \\
\hline $\mathrm{ZT}-5$ & 0.4 & 16 & $30 \pm 17$ & $27 \pm 1.3$ & $35.1 \pm 1.4$ & $466 \pm 19$ & $1.58 \pm 0.08$ & $0.97 \pm 0.04$ & $2.13 \pm 0.12$ \\
\hline
\end{tabular}

Table1 Summary of depth, water content (w.c.), radionuclide concentrations and quartz dose rates for the four debris flow samples. Water content is taken as midway between observed and saturated water content. An internal quartz dose rate of $0.06 \pm 0.03 \mathrm{mGy}$ a-1 has been assumed (Mejdahl, 1987). Total dose rate include cosmic rays and effect of water content. 


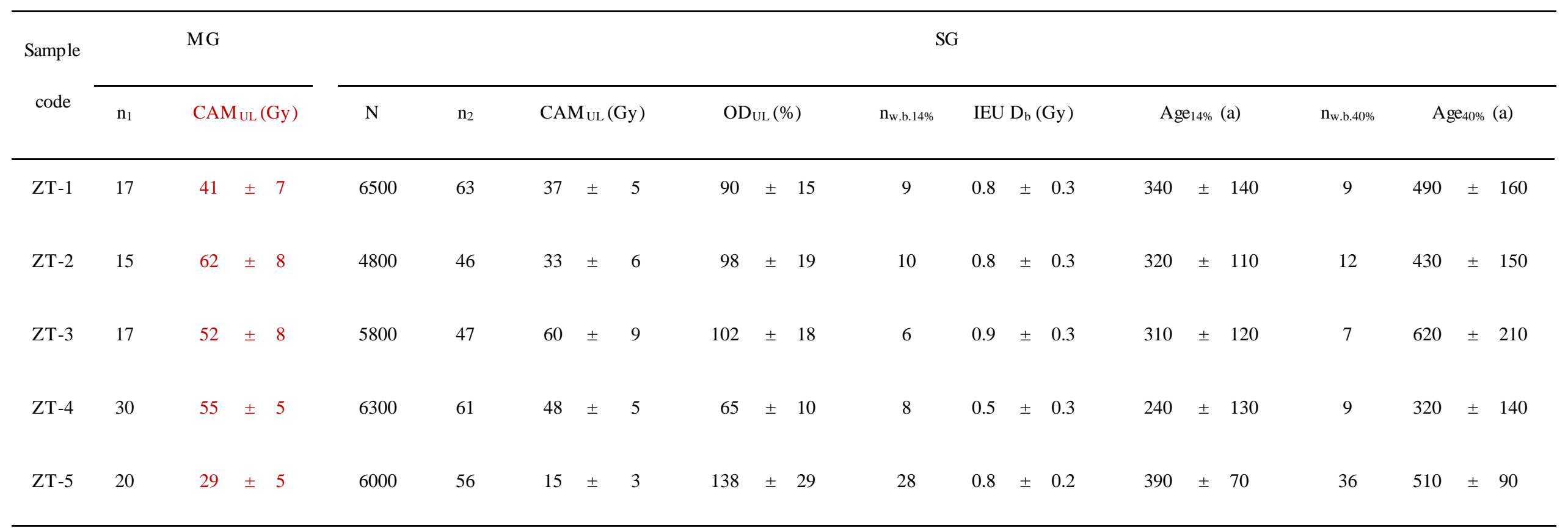

Table 2. Summary of synthetic multi-grain (MG) and single-grain (SG) results . 'MG' is simulated multi-grain measurements (i.e. synthetic aliquots, see text for details), 'SG' is single-grain

measurements, ' $\mathrm{n}_{1}$ ' is the number of accepted dose estimates from synthetic aliquots (i.e. summing of the single-grain data), 'N' is the number of measured single-grains, ' $\mathrm{n}_{2}$ ' is the number of accepted dose estimates from single-grain data, ' $\mathrm{n}_{\mathrm{w} . \mathrm{b}}$ ' is the number of grains identified to be well-bleached by the IEU minimum dose model using the given dispersion value $a$ (see text for details), 'IEU $\mathrm{D}_{\mathrm{b}}$ ' is the burial dose estimated using the IEU and 'Age' is the age derived using the IEU $\mathrm{D}_{\mathrm{b}}$ and the appropriate dose rate (see Table 1). 
Fig.1

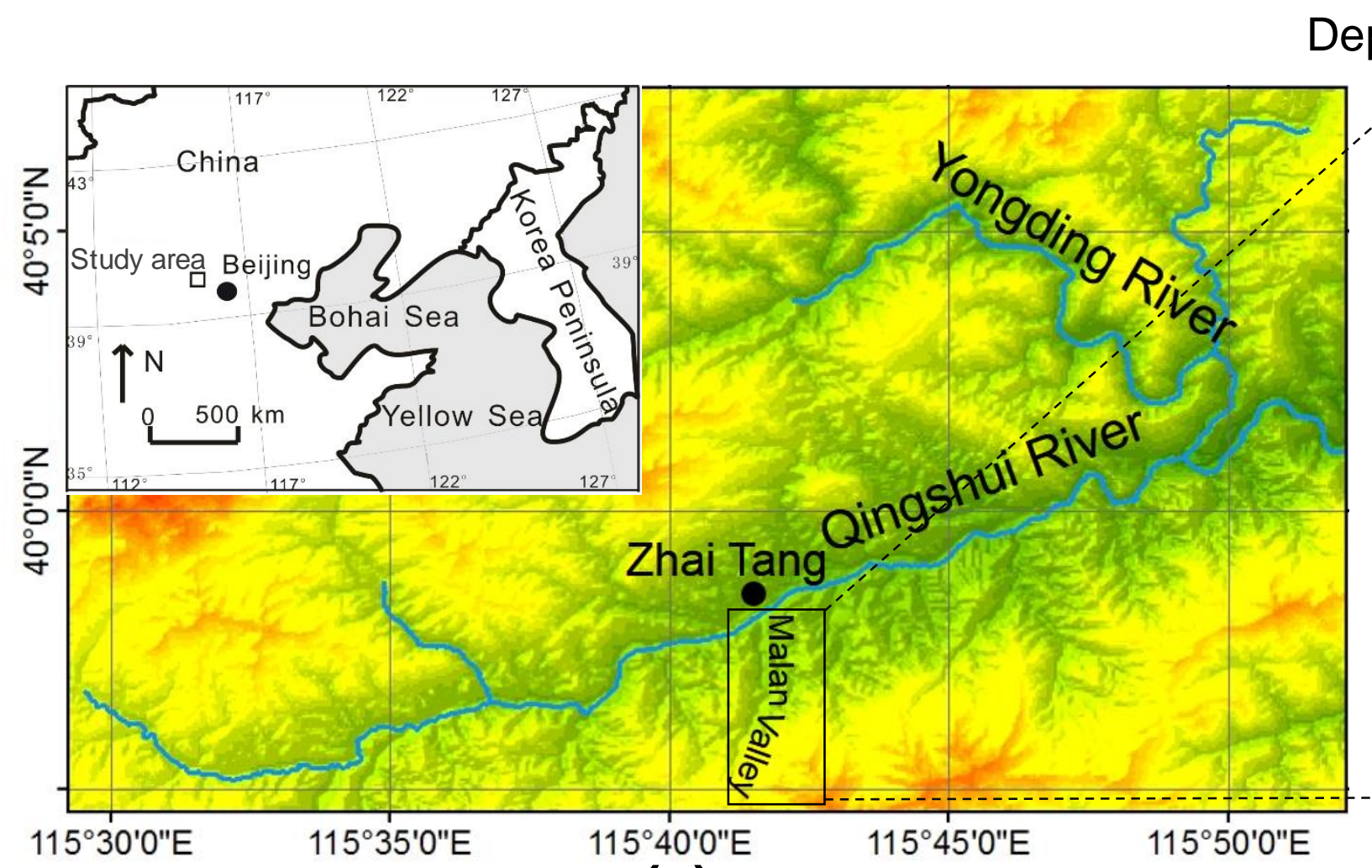

(a)

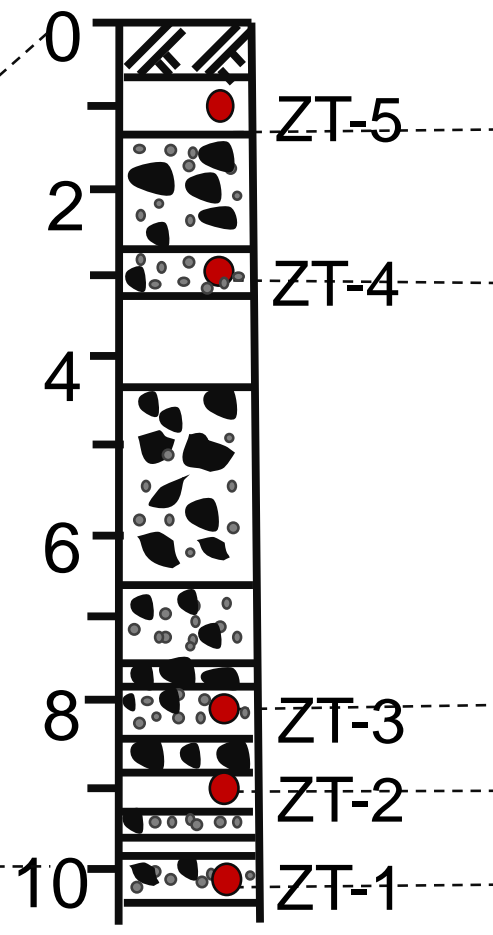

(b)

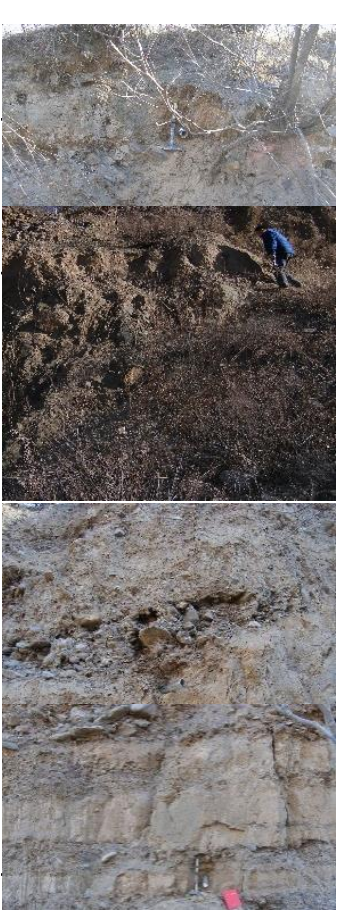

(c)

$\mathbb{R}$ Plough layer $\square$ Hybrid layer $\square$ Gravel layer $\square$ Sandy-silt 
Fig.2

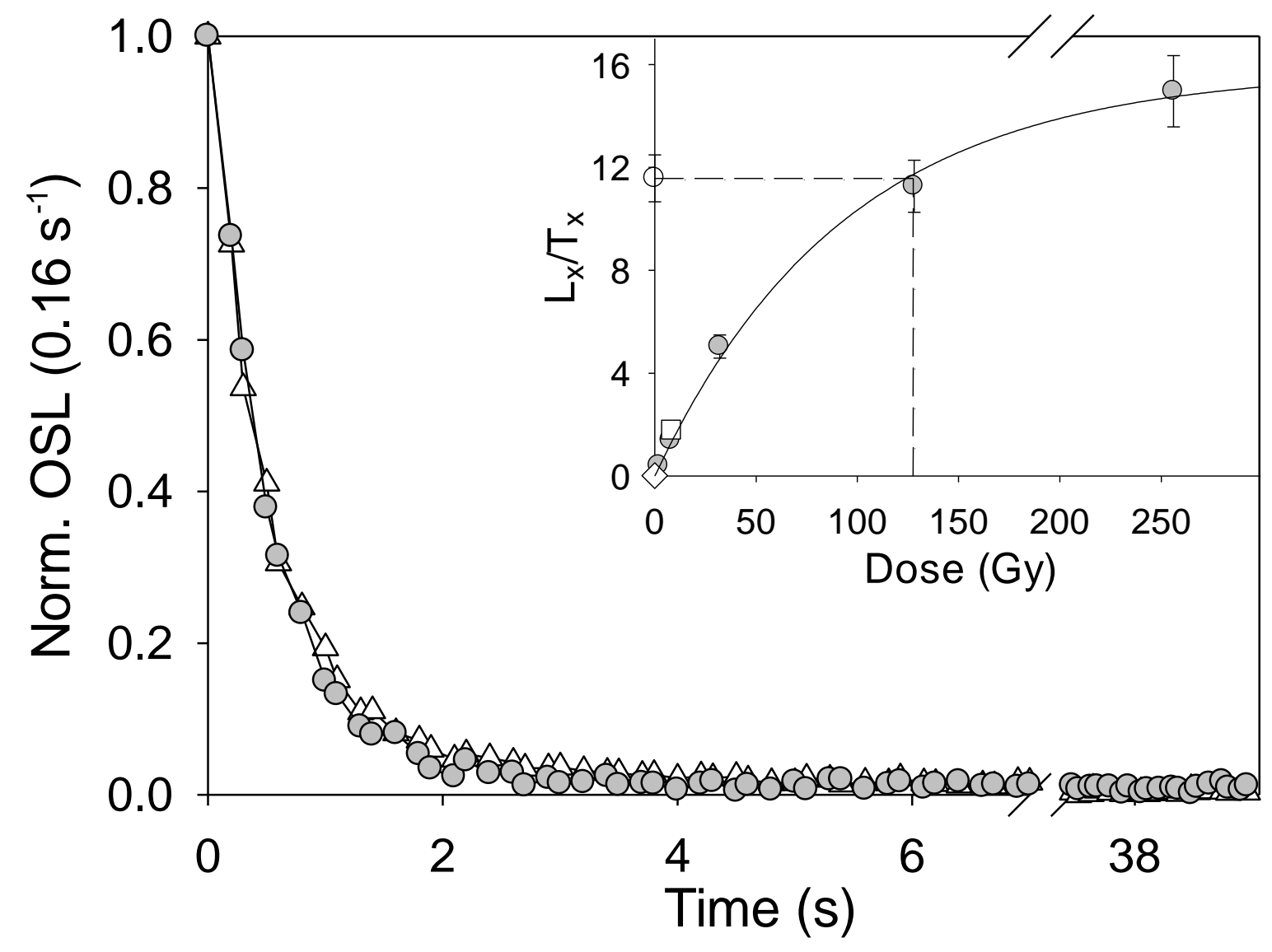


Fig. 3

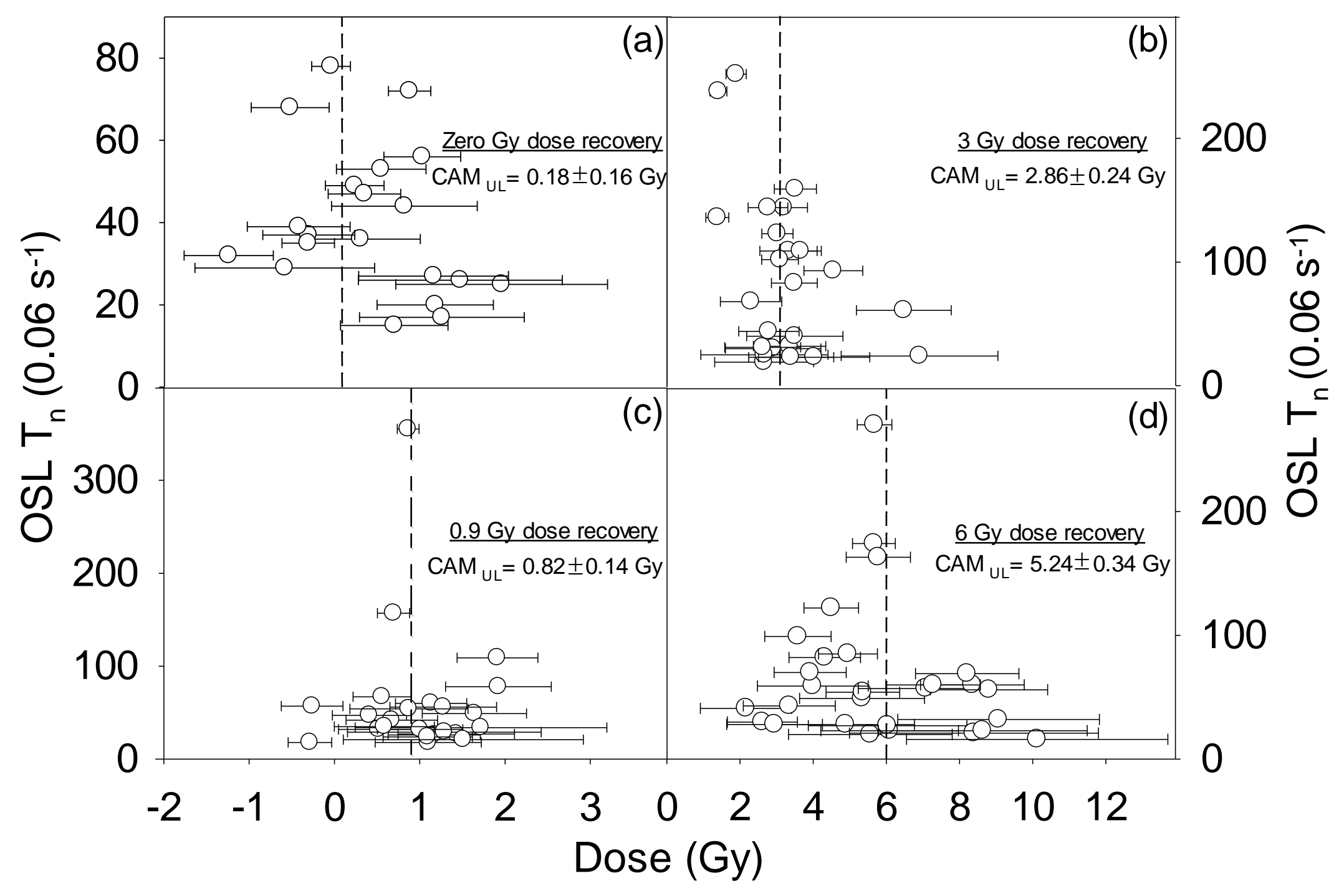


Fig.4

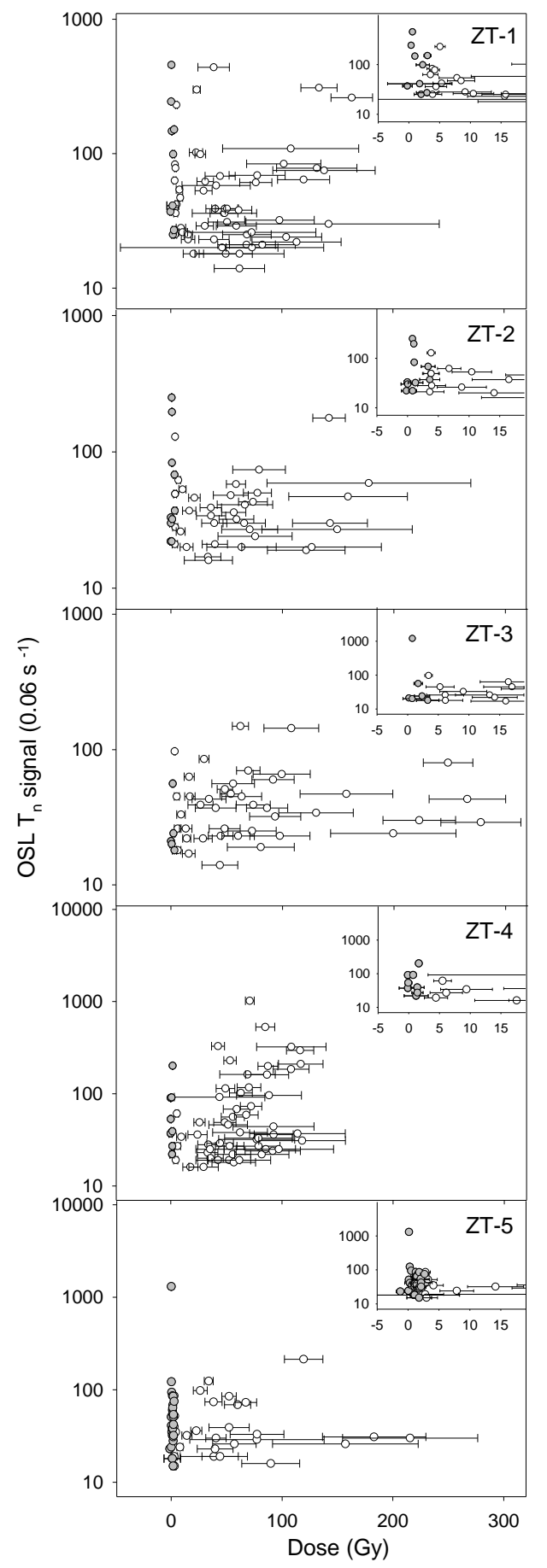


Fig.5

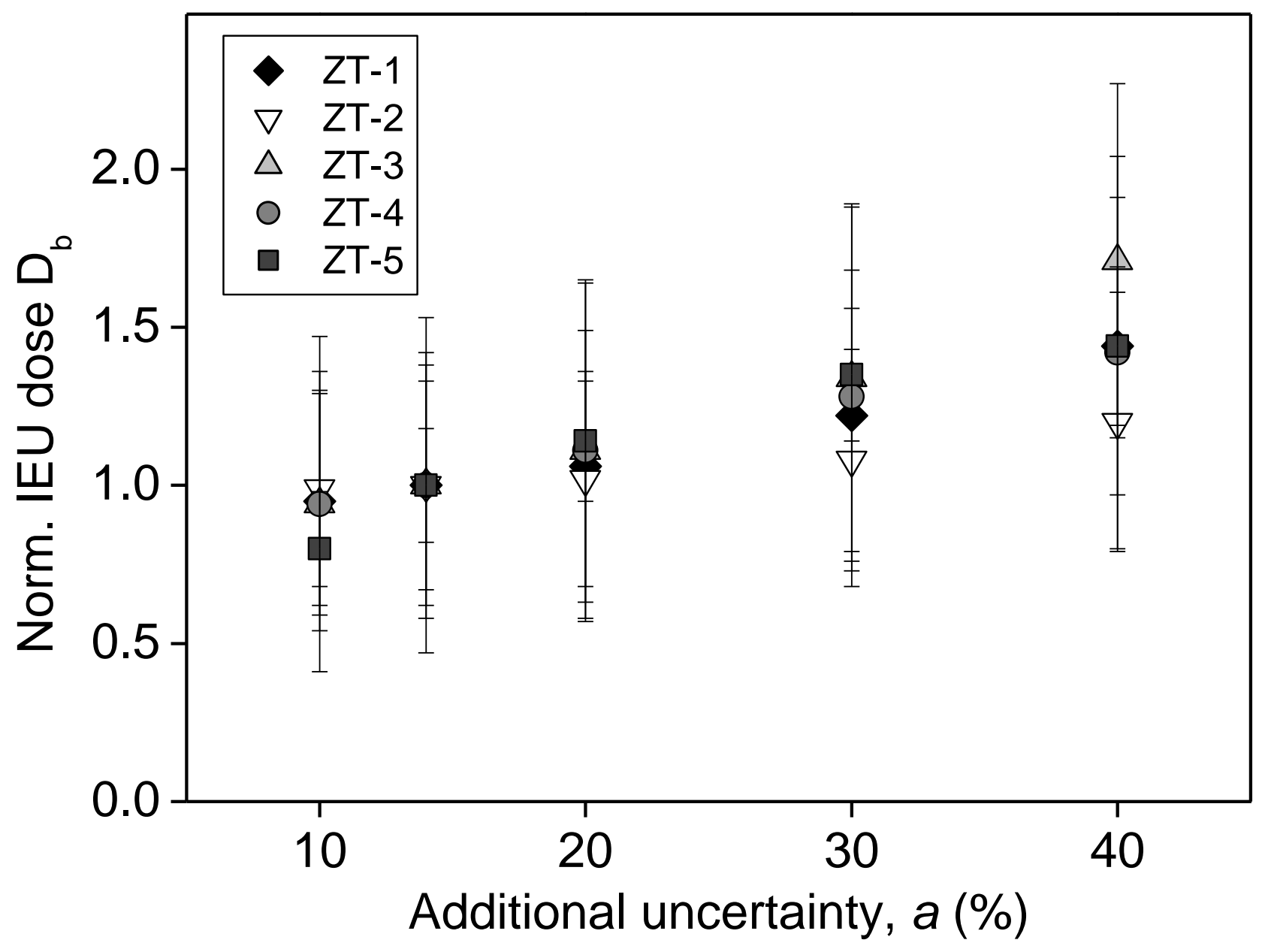

